\title{
Pre-travel Health Advice for Patients With Cardiovascular Disease
}

\author{
Chee Hwui Liew ${ }^{1,2,3}$, Gerard Thomas Flaherty ${ }^{1,3,4^{*}}$ \\ ${ }^{1}$ School of Medicine, National University of Ireland Galway, Galway, Ireland \\ ${ }^{2}$ School of Medicine, Trinity College Dublin, Dublin, Ireland \\ ${ }^{3}$ National Institute for Prevention and Cardiovascular Health, Galway, Ireland \\ ${ }^{4}$ School of Medicine, International Medical University, Kuala Lumpur, Malaysia
}

Corresponding Author: Gerard Thomas Flaherty, MD, Professor, School of Medicine, National University of Ireland Galway, Galway, Ireland. Tel: +353-91495469, Email: gerard.flaherty@nuigalway.ie

Received July 8, 2019; Accepted July 8, 2019; Online Published August 31, 2019

\begin{abstract}
Cardiovascular disease (CVD) is the leading cause of death among international travellers. Practitioner knowledge of the effects of CVD on international travel is imperative in order to promote a healthy travel experience. This review aimed to explore the available literature on this topic. The PubMed database was accessed to source relevant literature using combinations of relevant keywords as search terms. Articles were restricted to those published in the English language through March 2019. Of 1726 article records retrieved, 73 relevant papers were examined carefully. The results of this narrative review are related to multiple aspects of CVD and travel. The pre-travel consultation should address issues regarding vaccinations, travel insurance, anticoagulation, and medical devices. Additional vaccines to be discussed include influenza, pneumococcal, and hepatitis B. Patients with CVD should be advised of the need to carry a copy of their ECG, prescription(s), and pacemaker manufacturer's card. Knowledge of the location overseas of automated external defibrillators and awareness of health risks associated with strenuous adventure activities are important for CVD travellers. Medical tourism for patients with CVD is briefly considered. Space tourism is an emerging category of extreme international travel that requires specialized pre-travel preparation. This narrative review article highlights the gaps in the travel medicine literature in relation to CVD. A strong evidence base for most recommendations is lacking. Future scholarly efforts are warranted to facilitate more robust travel recommendations for CVD patients. No qualitative studies to date have described the experiences of international travellers with CVD.

Keywords: Cardiovascular Disease, Travel, Altitude, Medical Tourism, Medical Devices
\end{abstract}

Citation: Liew CH, Flaherty GT. Pre-travel health advice for patients with cardiovascular disease. Int J Travel Med Glob Health. 2019;7(3):79-85 doi:10.15171/ijtmgh.2019.18.

\section{Introduction}

International tourism, as a global economic sector, has experienced significant growth in recent decades. According to the World Tourism Organization, there were over 1.3 billion international tourist arrivals in 2017, and this figure is expected to reach 1.8 billion by $2030 .{ }^{1}$ Parallel to the growth in international travel is an increase in the incidence and prevalence of cardiovascular disease (CVD), which remains the leading cause of death globally. ${ }^{2}$ Importantly, the same phenomenon is also present among international travellers. ${ }^{3}$ Cardiac-related diseases commonly contribute to in-flight medical emergencies ${ }^{4,5}$; hence a sound knowledge of the relationship between CVD and international travel is of fundamental importance.

The effect of air travel on the cardiovascular system has been well studied. ${ }^{6}$ However, the extent to which CVD affects the experiences of international travellers has not previously been determined. A previous qualitative study examined the experiences of obese patients during international travel. ${ }^{7}$ Most patients perceived a health benefit to travel. Despite this, obesity was generally regarded as a considerable barrier to international travel. People with CVD may also find their travel experiences stressful owing to various difficulties related to their disease and its pharmacotherapy. These could range from issues encountered in the airport to limited participation in activities abroad owing to the fear of unpredictable medical events. The influence of travel on decompensation of pre-existing CVD has not been previously reviewed. Thus, there is a lack of guidance for travel medicine practitioners and specialist cardiologists when confronted

Copyright $(0) 2019$ The Author(s). This is an open-access article distributed under the terms of the Creative Commons Attribution License (http:// creativecommons.org/licenses/by/4.0), which permits unrestricted use, distribution, and reproduction in any medium, provided the original work is properly cited. 
with patients travelling with a cardiac history or CVD risk factors. This narrative review is the first to explore the recent literature on this novel topic which has been largely neglected in travel medicine.

\section{Methods}

\section{Search Srategy}

The PubMed database was accessed to source relevant literature. Combinations of the following keywords were used as search terms: 'cardiovascular', 'cardiac', 'heart', 'travel', 'travelling,' 'air travel', 'congenital heart disease,' 'stroke, 'cardiac device, 'airport', 'pacemaker, 'automated external defibrillator', 'microgravity', 'sport', 'adventure activity', 'adventure sports', 'diving, 'medical tourism', 'travel insurance', 'travellers', 'abroad, 'airplane', 'heart transplant', and 'medication'. Articles were restricted to those published in the English language through March 2019. Priority was given to articles published in the past 5 years. Articles that were not accessible in full text were excluded. Reference lists of the articles identified were screened for additional sources. The grey literature was also searched for relevant material (Figure 1).

\section{Results}

\section{Cardiovascular Conditions}

Heart Failure

Current recommendations based on a survey by Ingle et al state that air travel is generally safe in passengers with stable chronic heart failure (CHF) without the necessity of changes in medication or symptoms. ${ }^{8}$ Their study involved $464 \mathrm{CHF}$ patients. Notably, the travel destinations, hence the time spent on airplanes, were varied. This may impact the extent of hypoxia experienced during the journey by air. Another study illustrated that CHF symptoms did not worsen with reduced inspired oxygen in the cabin environment. ${ }^{9}$ For travellers with more severe CHF, e.g., New York Heart Association (NYHA) classification III or IV, oxygen supplementation is recommended. ${ }^{10}$ The use of in-flight oxygen supplementation may be an unpleasant experience for these travellers.

\section{Coronary Heart Disease}

Chest pain, or angina, associated with coronary heart disease (CHD) frequently precipitates flight diversions. ${ }^{5,11}$ At sea level, severe atherosclerotic lesions diminish oxygen availability in patients with CHD. This becomes crucial during air travel, as the angina threshold is often reduced due to physiologic changes. ${ }^{10} \mathrm{~A}$ comprehensive review by Smith et al outlined the suitability of air travel in patients with CHD. ${ }^{12}$ Their recommendations were mainly based on observational studies as well as analyses of in-flight medical emergencies. Notably, the data only involved air travel after uncomplicated myocardial infarction (MI). There may be nuances in outcomes for travellers with MI complicated by reduced ventricular function or arrhythmias.

\section{Stroke}

Cerebrovascular accident (CVA) or stroke patients may find

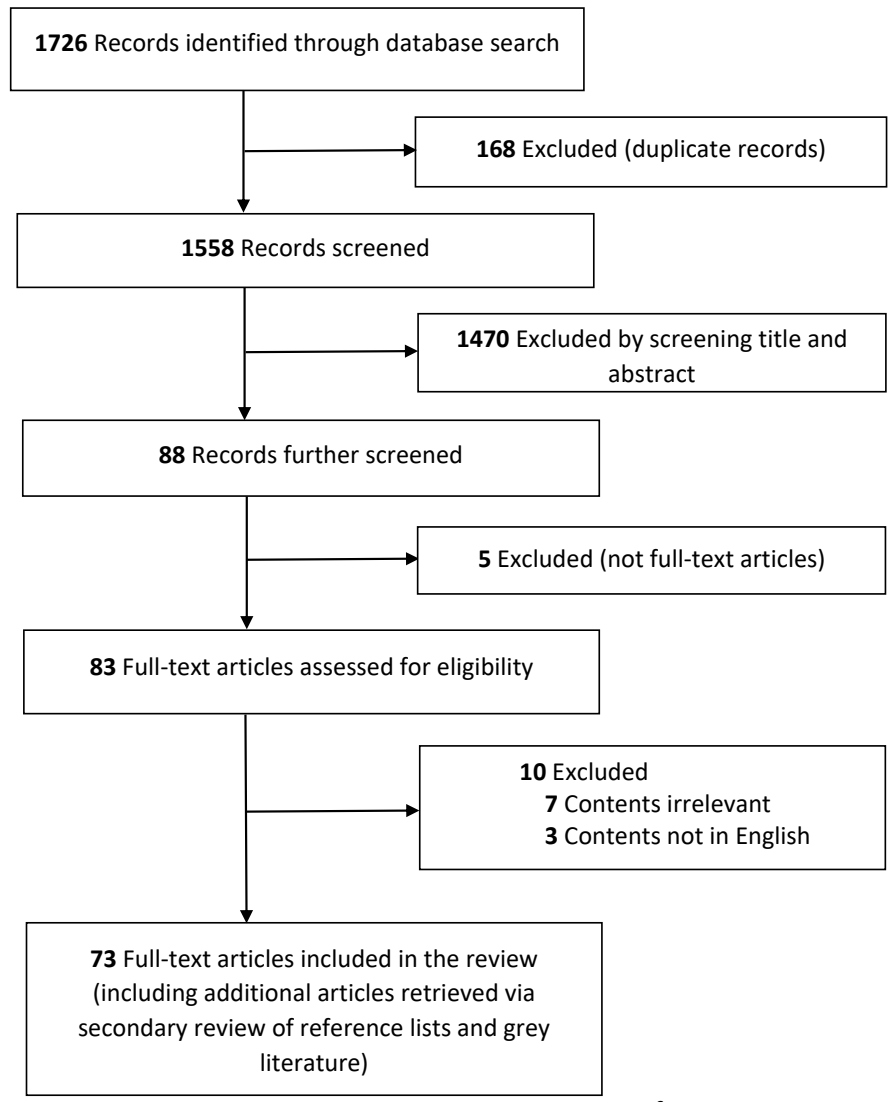

Figure 1. Study Flowchart for Article Selection. 
it challenging to pursue international travel due to impaired mobility. A comprehensive recommendation for air travellers with stroke is lacking. A review by Barros et al illustrated this significant gap in the literature. ${ }^{13}$ The International Air Transport Association states that air travel is permissible in stroke patients five to fourteen days post-event. ${ }^{14}$ Additionally, the use of in-flight supplemental oxygen is also recommended for these travellers. In contrast to the dearth of literature on air travel in stroke patients, there is abundant literature that describes in-flight and post-flight stroke incidence ${ }^{15-17}$ as well as repatriation due to CVA abroad. ${ }^{18,19}$

\section{Congenital Heart Disease}

The literature on congenital heart disease (CGHD) and air travel is limited. Harinck et al reported that it was generally safe to fly with CGHD. ${ }^{20}$ However, their study was underpowered with only twelve patients. Additionally, the risk was not stratified based on NYHA classification. More recently, a systematic review of eleven studies supported the recommendations from the Harinck study. ${ }^{21}$ The review only included observational studies; importantly, patients with cystic fibrosis were also present. This entailed a more complex analysis of the included studies.

\section{High Altitude Travel}

As mountain activities have evolved, e.g., skiing and snowboarding, the pursuance of high-altitude tourism (HAT) has become increasingly popular. ${ }^{22}$ High-altitude illnesses (HAI) secondary to hypoxia at decreased barometric pressure are well established. It is beyond the scope of this review to discuss HAI in detail. ${ }^{23}$ Pulmonary hypertension at high altitude has also been described. ${ }^{24,25}$ With these in mind, it is important for high-altitude travellers with CVD to be mindful of appropriate pre-travel preparations. ${ }^{26}$

High altitude affects underlying CVD in various ways, e.g. altered physiologic parameters and medication doses
(Table 1). A guideline by the Medical Commission of International Climbing and Mountaineering Federations may be a valuable resource in pre-travel consultations. ${ }^{28}$ Although comprehensive, the data reported was based solely on observational studies. Notably, recommendations for travellers with valvular heart disease or heart transplant were more limited. Pre-travel submaximal exercise testing has been proposed to have good predictive value, though its effectiveness requires validation in larger studies. ${ }^{29}$

\section{Activities, Sports, and Climate}

The pursuit of recreational activities during international travel is highly desirable. However, travellers with CVD may restrict themselves due to health concerns. A retrospective study in Austria showed that MI usually occurred within the first two days of initiating physical activities at travel destinations. ${ }^{30}$ Notably, the study had only 110 patients with a mean age of 60 years. The same phenomenon may not be evident in different age groups. Adventure water sports abroad have grown in popularity in the last century; accordingly, a pretravel medical evaluation is strongly recommended for these tourists. ${ }^{31}$ Currently, no guidelines specific to CVD patients in this regard are available. However, there is a wealth of literature in relation to diving. A cross-sectional study showed that CVD was highly prevalent among divers. ${ }^{32}$ Possible longterm cardiovascular effects from diving have been identified based on a study that compared the cardiovascular profiles of former divers and non-divers. ${ }^{33}$ It must be kept in mind that former divers and travellers who dive leisurely may not be directly comparable, as the latter tend to dive for a shorter period of time. Additionally, that study did not examine shortterm or immediate cardiovascular outcomes, e.g., occurrence of MI during diving. Nonetheless, cold water immersion from diving has been associated with cardiac arrhythmias, and thus a heightened awareness among CVD travellers is warranted. ${ }^{34}$

Extremes of climate can be significant for adventure

Table 1. Effects of High Altitude on Cardiovascular Disorders 27,28

\begin{tabular}{|c|c|}
\hline Issue & Health Effects and Clinical Recommendations \\
\hline \multirow{3}{*}{ Cardiovascular changes } & Small increase in systemic blood pressure \\
\hline & Increased heart rate and cardiac output through sympathetic vasoconstriction \\
\hline & Increased risk of ventricular tachyarrhythmias \\
\hline \multirow{3}{*}{ Medications } & Adjustments in antihypertensive medication doses may be required. \\
\hline & Dehydration from diuretics may be compounded. \\
\hline & Nifedipine prophylaxis for asymptomatic CHD patients with pulmonary hypertension may be required. \\
\hline \multirow{4}{*}{ Contraindications } & Altitude travel contraindicated for six months following MI \\
\hline & Altitude exposure contraindicated in symptomatic heart failure \\
\hline & No evidence for increased risk of CABG graft closure or PTCA stent re-stenosis \\
\hline & Physical exertion should be avoided during acclimatization \\
\hline \multirow{4}{*}{ General precautions } & Patients with stable CHD should tolerate travel up to $2500 \mathrm{~m}$. \\
\hline & Respiratory alkalosis, cold and sympathetic activation may reduce myocardial perfusion. \\
\hline & Lower angina threshold \\
\hline & Congenital heart disease patients are more susceptible to HAPE. \\
\hline
\end{tabular}

CABG: coronary artery bypass grafting; PTCA: percutaneous transluminal coronary angiography; HAPE: high altitude pulmonary oedema; CHD: coronary heart disease. 
travellers with CVD. Low temperature has been associated with MI. ${ }^{30}$ Conversely, CVD travellers may be more vulnerable to heat stress, especially those on beta blockers and diuretics, due to autonomic dysregulation ${ }^{35}$ and excessive fluid loss, ${ }^{36}$ respectively. In particular, hot temperatures have received considerable attention with regard to increased cardiovascular mortality in patients with established CVD. ${ }^{37,38}$

\section{Vaccinations}

Apart from the recommended travel vaccinations, additional vaccines may be recommended in CVD patients. ${ }^{27}$ A landmark study that systematically reviewed eight randomized controlled trials (RCTs) of 12000 patients highlighted the benefits of influenza vaccine in CVD. ${ }^{39}$ Notably, not all patients in the trials had established CHD; some belonged to the category of primary prevention patients. In contrast, no RCTs have evaluated the benefits of pneumococcal vaccine in CVD, although retrospective studies have shown advantages. ${ }^{40,41} \mathrm{~A}$ strong evidence base for hepatitis B vaccine in CVD patients is lacking, despite being generally recommended in this traveller group who may be at increased risk of nosocomial transmission of hepatitis B. ${ }^{27}$ In fact, a recent study showed that hepatitis $\mathrm{B}$ infection did not increase CHD risk. ${ }^{42}$ However, that study only involved cohort and case-control studies. Table 2 summarizes the current recommendations for influenza and pneumococcal vaccinations in the most recent European Society of Cardiology (ESC) guidelines. Importantly, the level of recommendation varies according to individual published guidelines.

\section{Travel Insurance}

The importance of travel insurance (hereafter termed 'insurance') in CVD patients has previously been highlighted. ${ }^{27,44}$ However, patients may face obstacles when obtaining insurance. In particular, people with CGHD are often denied coverage. ${ }^{45,46}$ This leads to the practice of not declaring their condition in order to become insurance-eligible. ${ }^{47}$ Insurance is crucial as cardiac emergencies are among the most common conditions for aeromedical evacuation which is generally covered by insurance. ${ }^{48}$ Therefore, it is imperative for travellers with any cardiac condition to be medically covered in order to access medical care abroad if required. Indeed, emergency medical assistance service (EMAS) was perceived to be fundamental by international travellers based on a recent survey. ${ }^{49}$ The study did not exclusively include travellers with CVD. Importantly, about 30\% of travellers were not aware of EMAS abroad. ${ }^{49}$

\section{Medical Tourism}

In recent years, medical tourism has proliferated such that there are now dedicated commercial agencies offering medical tourism packages to clients. ${ }^{50}$ It is estimated that 1.9 million travellers will seek medical care outside the United States in 2019. ${ }^{51}$ Cardiac surgery, including coronary artery bypass graft surgery, is one of the most common procedures sought by medical tourists abroad. ${ }^{50,52}$ Several Asian countries, including Thailand and India, are well-known medical tourism destinations for cardiac surgery, mainly due to lower costs. ${ }^{53}$ However, a caveat revolves around the quality of care provided to travellers who have received cardiac surgery abroad, and prospective medical tourists should be aware of these quality concerns. ${ }^{54}$

\section{Anticoagulation}

As international travel expands, physicians' knowledge of the agents available for anticoagulation in CVD patients is essential. ${ }^{55} \mathrm{New}$ oral anticoagulants (NOACs) like rivaroxaban and dabigatran are now in widespread use. ${ }^{56}$ NOACs have increased in popularity due to reduced pharmacologic interactions and the lack of routine international normalized ratio (INR) monitoring during international travel. A potential worry is the bleeding risk associated with NOACs. A landmark study of 72000 patients demonstrated that NOACs had similar bleeding event rates as warfarin, with a favorable risk-benefit profile. ${ }^{57}$ As NOACs are relatively new, most anticoagulated travellers will be taking warfarin. No previous study has examined their difficulty in monitoring INR overseas. Anticoagulated individuals may be assumed to bleed more when receiving pre-travel vaccinations; however, an RCT in Spain involving 229 patients showed that intramuscular injection of the influenza vaccine did not result in more bleeding than the subcutaneous route. ${ }^{58}$

\section{Medical Devices and Automated External Defibrillators} Literature on implanted cardiac devices in relation to international travel is sparse. These devices, like permanent pacemakers and implanted cardioverter-defibrillators, may add complexity when passing through airport security checkpoints. The fear of electromagnetic interference with these devices may concern some travellers. ${ }^{59}$ Modern devices are well shielded, however, and seem to be unaffected by both metal detector gates ${ }^{60}$ and hand-held metal detectors. ${ }^{61}$ However, if concerns arise, a pat down manual search may be considered. ${ }^{12}$ Prior communication with the airport authority is recommended. A device card and physician letter should

Table 2. Graded Recommendations for Influenza And Pneumococcal Vaccination in the Current Guidelines of the European Society of Cardiology ${ }^{43}$

\begin{tabular}{lcc}
\hline Type of Guidelines & Year of Publication & Recommended Vaccination \\
\hline Prevention of cardiovascular diseases & 2016 & Influenza \\
Acute and chronic heart failure - prevention and treatment & 2016 & Influenza and pneumococcal \\
$\begin{array}{l}\text { Pulmonary hypertension } \\
\text { Stable coronary artery disease }\end{array}$ & 2015 & Influenza and pneumococcal \\
\hline
\end{tabular}


also be carried by the traveller. ${ }^{27}$

Knowledge of the location of automated external defibrillators (AEDs) among international travellers is inadequate based on an airport survey. ${ }^{62}$ Nonetheless, locations of AEDs should be more publicly accessible to facilitate their retrieval when needed ${ }^{63-65}$; this is particularly crucial if the traveller is not familiar with the surroundings abroad. Technological inventions, e.g., a verified mobile AED map ${ }^{66}$ and medical drones, ${ }^{67}$ may potentially serve as useful aids for international travellers in the future.

\section{Microgravity in Space Tourism}

Space tourism is no longer a fantasy, with the first "space tourist", Dennis Tito, spending a week on board the International Space Station in 2001. ${ }^{68}$ The presence of a dedicated society as well as research plans herald a potential growth in this sector. ${ }^{69}$ The cardiovascular effects of microgravity in space tourism have been identified, e.g. altered orthostatic tolerance and increased risk of cardiac arrhythmia. ${ }^{70,71}$ Accordingly, it would be ideal for travel medicine physicians, cardiologists, and general practitioners to have a basic knowledge of the health risks associated with space tourism. In addition, space travellers with CVD should obtain appropriate pre-travel advice. Use of an artificial gravity system has been shown to alleviate some of the cardiovascular effects ${ }^{72}$; perhaps this will augment the safety features in future spacecrafts. It remains to be seen what adaptations will have to be made for cardiopulmonary resuscitation to make it suitable in the microgravity environment. ${ }^{73}$ The travel medicine physician of the near future may require sufficient knowledge of space physiology and the cardiovascular effects of microgravity to provide reasonable counsel to patients at risk of coronary events during commercial space flights.

\section{Conclusion and Recommendations for Future Research}

The available literature suggests that international travel is generally safe in stable, well-prepared CVD patients. The pursuit of high-altitude tourism, space tourism, and terrestrial and aquatic adventure activities may not be suitable for all CVD travellers owing to the potentially heightened health risks involved. Adequate pre-travel consultations would address issues regarding vaccinations, travel insurance, anticoagulation, medical tourism, and medical devices. Knowledge of AEDs among CVD travellers is important, yet lacking. In addition, knowledge of space tourism among healthcare providers would be desirable.

This review has highlighted both the paucity of literature in relation to CVD and international travel as well as the gaps in the available literature. Future high-quality research with larger sample sizes is warranted to generate robust travel recommendations for CVD patients, in particular, recommendations for those with stroke and congenital heart disease. The safety of adventure water sports in CVD patients also requires validation. Solutions for difficulties in obtaining travel insurance should be explored to ensure optimal accessibility of emergency medical assistance abroad, if needed. Notably, no literature has described the international travel
Review Highlights

What Is Already Known?

CVD is the most common cause of death in international travellers. Appropriate travel recommendations and adequate pre-travel preparations are crucial, yet clinical guidance is lacking in the travel medicine literature.

\section{What This Study Adds?}

This narrative review article describes the available literature in relation to CVD and international travel with an emphasis on air travel. It is generally safe for patients with CVD to travel abroad, although the recommendations vary slightly according to individual conditions. The risks posed by high-altitude tourism, adventure water sports, and medical tourism are considered. Evidence on vaccinations, travel insurance, anticoagulation, and medical devices are highlighted. The lack of knowledge of automated external defibrillators is discussed. Cardiovascular effects in the microgravity environment of space are explored. Further research is warranted to address the paucity of literature available in this subject.

experiences of CVD patients. We are currently undertaking a qualitative study on this topic. It is hoped that the findings from this study will reduce the travel health risk of CVD patients, contribute to better travel recommendations, and importantly, foster an optimal and enjoyable travel experience for this vulnerable group of travellers.

\section{Authors' Contributions}

GTF was responsible for study conception. CHL and GTF designed the study. CHL conducted the literature search and prepared the first draft of the manuscript. GTF edited the draft manuscript for significant intellectual content. Both authors read and approved the final version of the manuscript.

\section{Conflict of Interest Disclosures}

The authors declare that they have no conflicts of interest.

\section{Ethical Approval}

Not applicable.

\section{Funding/Support}

None.

\section{References}

1. World Tourism Organization. UNWTO Annual Report, 2017. http://publications.unwto.org/publication/unwto-annualreport-2017. Accessed March 1, 2019.

2. Piepoli MF, Hoes AW, Agewall S, et al. 2016 European Guidelines on cardiovascular disease prevention in clinical practice: The Sixth Joint Task Force of the European Society of Cardiology and Other Societies on Cardiovascular Disease Prevention in Clinical Practice (constituted by representatives of 10 societies and by invited experts) Developed with the special contribution of the European Association for Cardiovascular Prevention \& 
Rehabilitation (EACPR). Eur Heart J. 2016;37(29):2315-2381. doi:10.1093/eurheartj/ehw106.

3. Wieten RW, van der Schalie M, Visser BJ, Grobusch MP, van Vugt M. Risk factors and pre-travel healthcare of international travellers attending a Dutch travel clinic: a cross-sectional analysis. Travel Med Infect Dis. 2014;12(5):511-524. doi:10.1016/j. tmaid.2014.05.004.

4. Valani R, Cornacchia M, Kube D. Flight diversions due to onboard medical emergencies on an international commercial airline. Aviat Space Environ Med. 2010;81(11):1037-1040. doi:10.3357/ ASEM.2789.2010.

5. Chandra A, Conry S. In-flight medical emergencies. West J Emerg Med. 2013;14(5):499-504. doi:10.5811/westjem.2013.4.16052.

6. Oliveira-Silva I, Leicht AS, Moraes MR, et al. Heart rate and cardiovascular responses to commercial flights: relationships with physical fitness. Front Physiol. 2016;7:648. doi:10.3389/ fphys.2016.00648.

7. Flaherty GT, Geoghegan R, Brown IG, Finucane FM. Severe obesity as a barrier to international travel: a qualitative analysis. J Travel Med. 2019;26(3). doi:10.1093/jtm/taz018.

8. Ingle L, Hobkirk J, Damy T, Nabb S, Clark AL, Cleland JG. Experiences of air travel in patients with chronic heart failure. Int J Cardiol. 2012;158(1):66-70. doi:10.1016/j.ijcard.2010.12.101.

9. Hobkirk JP, Damy T, Walters M, et al. Effects of reducing inspired oxygen concentration for one hour in patients with chronic heart failure: implications for air travel. Eur J Heart Fail. 2013;15(5):505510. doi:10.1093/eurjhf/hft003.

10. Hammadah M, Kindya BR, Allard-Ratick MP, et al. Navigating air travel and cardiovascular concerns: Is the sky the limit? Clin Cardiol. 2017;40(9):660-666. doi:10.1002/clc.22741.

11. Silverman D, Gendreau M. Medical issues associated with commercial flights. Lancet. 2009;373(9680):2067-2077. doi:10.1016/s0140-6736(09)60209-9.

12. Smith $D$, Toff $W$, Joy $M$, et al. Fitness to fly for passengers with cardiovascular disease. Heart. 2010;96 Suppl 2:ii1-16. doi:10.1136/hrt.2010.203091.

13. Barros A, Duchateau FX, Huff JS, Verner L, O'Connor RE, Brady WJ. Nonurgent commercial air travel after nonhemorrhagic cerebrovascular accident. Air Med J. 2014;33(3):106-108. doi:10.1016/j.amj.2014.02.003.

14. International Air Transport Association (IATA). Medical Manual, 2018. https://www.iata.org/publications/Pages/medical-manual. aspx. Accessed March 1, 2019.

15. Alonso-Cánovas A, de Felipe-Mimbrera A, González-Valcárcel J, García-Barragán N, Corral I, Masjuan J. Neurology at the airport. J Neurol Neurosurg Psychiatry. 2011;82(9):981-985. doi:10.1136/ jnnp.2011.243709.

16. Humaidan H, Yassi N, Weir L, Davis SM, Meretoja A. Airplane stroke syndrome. J Clin Neurosci. 2016;29:77-80. doi:10.1016/j. jocn.2015.12.015

17. Álvarez-Velasco R, Masjuan J, DeFelipe A, et al. Stroke in commercial flights. Stroke. 2016;47(4):1117-1119. doi:10.1161/ strokeaha.115.012637

18. Sand M, Bollenbach $M$, Sand D, et al. Epidemiology of aeromedical evacuation: an analysis of 504 cases. J Travel Med. 2010;17(6):405-409. doi:10.1111/j.1708-8305.2010.00454.x.

19. Hasler RM, Albrecht S, Exadaktylos AK, Albrecht R. Repatriations and 28-day mortality of ill and injured travellers: 12 years of experience in a Swiss emergency department. Swiss Med Wkly. 2015;145:w14208. doi:10.4414/smw.2015.14208.

20. Harinck E, Hutter PA, Hoorntje TM, et al. Air travel and adults with cyanotic congenital heart disease. Circulation. 1996;93(2):272276. doi:10.1161/01.cir.93.2.272.

21. Spoorenberg ME, van den Oord MH, Meeuwsen T, Takken T. Fitness to fly testing in patients with congenital heart and lung disease.
Aerosp Med Hum Perform. 2016;87(1):54-60. doi:10.3357/ amhp.4408.2016.

22. Windsor JS, Firth PG, Grocott MP, Rodway GW, Montgomery HE. Mountain mortality: a review of deaths that occur during recreational activities in the mountains. Postgrad Med J. 2009;85(1004):316-321. doi:10.1136/pgmj.2009.078824.

23. Bärtsch P, Swenson ER. Acute high-altitude illnesses. N Engl J Med. 2013;368(24):2294-2302.doi:10.1056/NEJMcp1214870.

24. Smith TG, Talbot NP, Chang RW, et al. Pulmonary artery pressure increases during commercial air travel in healthy passengers. Aviat Space Environ Med. 2012;83(7):673-676. doi:10.3357/ ASEM.3235.2012.

25. Grimminger J, Richter M, Tello K, Sommer N, Gall H, Ghofrani HA. Thin air resulting in high pressure: mountain sickness and hypoxia-induced pulmonary hypertension. Can Respir J. 2017;2017:8381653. doi:10.1155/2017/8381653.

26. Flaherty GT, Kennedy KM. Preparing patients for travel to high altitude: advice on travel health and chemoprophylaxis. $\mathrm{Br} \mathrm{J}$ Gen Pract. 2016;66(642):e62-64. doi:10.3399/bjgp16X683377.

27. Flaherty G, De Freitas S. A Heart for Travel: Travel Health Considerations for Patients with Heart Disease and Cardiac Devices. Ir Med J. 2016;109(10):486.

28. Donegani E, Hillebrandt D, Windsor J, et al. Pre-existing cardiovascular conditions and high altitude travel. Consensus statement of the Medical Commission of the Union Internationale des Associations d'Alpinisme (UIAA MedCom) Travel Medicine and Infectious Disease. Travel Med Infect Dis. 2014;12(3):237252. doi:10.1016/j.tmaid.2014.02.004.

29. Burtscher M, Philadelphy M, Gatterer H, Burtscher J, Likar R. Submaximal exercise testing at low altitude for prediction of exercise tolerance at high altitude. J Travel Med. 2018;25(1). doi:10.1093/jtm/tay011.

30. Klug G, Schenk S, Dorler J, et al. Occurrence of acute myocardial infarction in winter tourists: data from a retrospective questionnaire. Clin Res Cardiol. 2011;100(8):669-674. doi:10.1007/s00392-0110294-3.

31. Nathanson AT, Young JM, Young C. Pre-participation medical evaluation for adventure and wilderness watersports. Clin J Sport Med. 2015;25(5):425-431. doi:10.1097/jsm.0000000000000252.

32. Lippmann J, Mc DTD, Stevenson C, Williams J, Mitchell SJ. Diving with pre-existing medical conditions. Diving Hyperb Med. 2017;47(3):180-190. doi:10.28920/dhm47.3.180-190.

33. Åsmul K, Irgens $\AA$, Grønning M, Møllerløkken A. Diving and longterm cardiovascular health. Occup Med (Lond). 2017;67(5):371376. doi:10.1093/occmed/kqx049.

34. Shattock MJ, Tipton MJ. 'Autonomic conflict': a different way to die during cold water immersion? J Physiol. 2012;590(14):3219-3230. doi:10.1113/jphysiol.2012.229864.

35. Kenny GP, Yardley J, Brown C, Sigal RJ, Jay O. Heat stress in older individuals and patients with common chronic diseases. Cmaj. 2010;182(10):1053-1060. doi:10.1503/cmaj.081050.

36. Cui J, Sinoway LI. Cardiovascular responses to heat stress in chronic heart failure. Curr Heart Fail Rep. 2014;11(2):139-145. doi:10.1007/s11897-014-0191-y.

37. Baaghideh M, Mayvaneh F. Climate change and simulation of cardiovascular disease mortality: A case study of Mashhad, Iran. Iran J Public Health. 2017;46(3):396-407.

38. Sanderson M, Arbuthnott K, Kovats S, Hajat S, Falloon P. The use of climate information to estimate future mortality from high ambient temperature: A systematic literature review. PLoS One. 2017;12(7):e0180369. doi:10.1371/journal.pone.0180369.

39. Clar C, Oseni Z, Flowers N, Keshtkar-Jahromi M, Rees K. Influenza vaccines for preventing cardiovascular disease. Cochrane Database Syst Rev. 2015(5):Cd005050. doi:10.1002/14651858. CD005050.pub3. 
40. Corrales-Medina VF, Alvarez KN, Weissfeld LA, et al. Association between hospitalization for pneumonia and subsequent risk of cardiovascular disease. JAMA. 2015;313(3):264-274. doi:10.1001/ jama.2014.18229.

41. Ren S, Newby D, Li SC, et al. Effect of the adult pneumococcal polysaccharide vaccine on cardiovascular disease: a systematic review and meta-analysis. Open Heart. 2015;2(1):e000247. doi:10.1136/openhrt-2015-000247.

42. Wijarnpreecha K, Thongprayoon C, Panjawatanan P, Ungprasert P. Hepatitis B virus infection and risk of coronary artery disease: a meta-analysis. Ann Transl Med. 2016;4(21):423. doi:10.21037/ atm.2016.11.12.

43. CiszewskiA. Cardioprotective effect of influenza and pneumococcal vaccination in patients with cardiovascular diseases. Vaccine. 2018;36(2):202-206. doi:10.1016/j.vaccine.2017.11.078.

44. Leggat PA, Griffiths R, Leggat FW. Emergency assistance provided abroad to insured travellers from Australia. Travel Med Infect Dis. 2005;3(1):9-17. doi:10.1016/j.tmaid.2004.07.002.

45. Crossland DS, Jackson SP, Lyall $R$, et al. Life insurance and mortgage application in adults with congenital heart disease. Eur J Cardiothorac Surg. 2004;25(6):931-934. doi:10.1016/j. ejcts.2004.01.040.

46. Ladouceur M, Iserin L, Cohen S, Legendre A, Boudjemline $\mathrm{Y}$, Bonnet D. Key issues of daily life in adults with congenital heart disease. Arch Cardiovasc Dis. 2013;106(6-7):404-412. doi:10.1016/j.acvd.2013.02.004

47. Pickup L, Bowater S, Thorne S, Clift P, Hudsmith L. Travel insurance in adult congenital heart disease - Do they declare their condition? Int J Cardiol. 2016;223:316-317. doi:10.1016/j. ijcard.2016.08.098.

48. Teichman PG, Donchin Y, Kot RJ. International aeromedical evacuation. N Engl J Med. 2007;356(3):262-270. doi:10.1056/ NEJMra063651.

49. Lee YH, Lu CW, Wu PZ, Huang HL, Wu YC, Huang KC. Attitudes and awareness of medical assistance while traveling abroad. Global Health. 2018;14(1):67. doi:10.1186/s12992-018-0382-5.

50. Alleman BW, Luger T, Reisinger HS, Martin R, Horowitz MD, Cram P. Medical tourism services available to residents of the United States. J Gen Intern Med. 2011;26(5):492-497. doi:10.1007/ s11606-010-1582-8.

51. Patients Beyond Borders. Medical Tourism Statistics and Facts, 2019. Available at: https://patientsbeyondborders.com/medicaltourism-statistics-facts. Accessed February 28, 2019.

52. Jacobs JP, Horowitz MD, Mavroudis C, Siegel A, Sade RM. Surgical tourism: the role of cardiothoracic surgery societies in evaluating international surgery centers. Ann Thorac Surg. 2013;96(1):8-14. doi:10.1016/j.athoracsur.2013.02.058.

53. Horowitz MD, Rosensweig JA, Jones CA. Medical tourism: globalization of the healthcare marketplace. MedGenMed. 2007;9(4):33.

54. Sade RM, Kavarana MN. Surgical ethics: today and tomorrow. Future Cardiol. 2017;13(6):567-578. doi:10.2217/fca-2017-0057.

55. Nunnally B, Josseaume J, Duchateau FX, O'Connor RE, Verner L, Brady WJ. Anticoagulation and Non-urgent Commercial Air Travel: A Review of the Literature. Air Med J. 2015;34(5):269-277. doi:10.1016/j.amj.2015.06.006.

56. Ringwald J, Grauer M, Eckstein R, Jelinek T. The place of new oral anticoagulants in travel medicine. Travel Med Infect Dis. 2014;12(1):7-19. doi:10.1016/j.tmaid.2013.11.005.

57. Ruff CT, Giugliano RP, Braunwald E, et al. Comparison of the efficacy and safety of new oral anticoagulants with warfarin in patients with atrial fibrillation: a meta-analysis of randomised trials. Lancet. 2014;383(9921):955-962. doi:10.1016/s01406736(13)62343-0.

58. Casajuana J, Iglesias B, Fàbregas M, et al. Safety of intramuscular influenza vaccine in patients receiving oral anticoagulation therapy: a single blinded multi-centre randomized controlled clinical trial. BMC Blood Disord. 2008;8:1. doi:10.1186/14712326-8-1.

59. Niehaus $M$, Tebbenjohanns J. Electromagnetic interference in patients with implanted pacemakers or cardioverter-defibrillators. Heart. 2001;86(3):246-248. doi:10.1136/heart.86.3.246.

60. Kolb C, Schmieder S, Lehmann G, et al. Do airport metal detectors interfere with implantable pacemakers or cardioverterdefibrillators? J Am Coll Cardiol. 2003;41(11):2054-2059. doi:10.1016/s0735-1097(03)00424-8.

61. Jilek $\mathrm{C}$, Tzeis $\mathrm{S}$, Vrazic $\mathrm{H}$, et al. Safety of screening procedures with hand-held metal detectors among patients with implanted cardiac rhythm devices: a cross-sectional analysis. Ann Intern Med. 2011;155(9):587-592. doi:10.7326/0003-4819-155-9201111010-00005.

62. Aagaard R, Grove EL, Mikkelsen R, Wolff A, Iversen KW, Løfgren B. Limited public ability to recognise and understand the universal sign for automated external defibrillators. Heart. 2016;102(10):770-774. doi:10.1136/heartjnl-2015-308700.

63. Leung $A C$, Asch DA, Lozada $\mathrm{KN}$, et al. Where are lifesaving automated external defibrillators located and how hard is it to find them in a large urban city? Resuscitation. 2013;84(7):910-914. doi:10.1016/j.resuscitation.2013.01.010.

64. Ho CL, Lui CT, Tsui KL, Kam CW. Investigation of availability and accessibility of community automated external defibrillators in a territory in Hong Kong. Hong Kong Med J. 2014;20(5):371-378. doi:10.12809/hkmj144258.

65. Griffis HM, Band RA, Ruther M, et al. Employment and residential characteristics in relation to automated external defibrillator locations. Am Heart J. 2016;172:185-191. doi:10.1016/j. ahj.2015.09.022.

66. Sakai $T$, Iwami $T$, Kitamura $T$, et al. Effectiveness of the new 'Mobile AED Map' to find and retrieve an AED: A randomised controlled trial. Resuscitation. 2011;82(1):69-73. doi:10.1016/j. resuscitation.2010.09.466.

67. Pulver A, Wei R, Mann C. Locating AED enabled medical drones to enhance cardiac arrest response times. Prehosp Emerg Care. 2016;20(3):378-389. doi:10.3109/10903127.2015.1115932.

68. Cater Cl. Steps to Space; opportunities for astrotourism. Tour Manag. 2010;31(6):838-845.doi:10.1016/j.tourman.2009.09.001.

69. Space Tourism Society. 2019. http://spacetourismsociety.org/. Accessed March 27, 2019.

70. Tanaka K, Nishimura N, Kawai Y. Adaptation to microgravity, deconditioning, and countermeasures. J Physiol Sci. 2017;67(2):271_ 281. doi:10.1007/s12576-016-0514-8.

71. Flaherty GT, Kenny-Gibson W, Lang MJ. The Final Frontier-What Should the Travel Medicine Practitioner Know About Space Flight Participation? J Travel Med. 2015;22(6):425-427. doi:10.1111/ jtm.12242.

72. Evans JM, Knapp CF, Goswami N. Artificial gravity as a countermeasure to the cardiovascular deconditioning of spaceflight: gender perspectives. Front Physiol. 2018;9:716. doi:10.3389/fphys.2018.00716.

73. Braunecker S, Douglas B, Hinkelbein J. Comparison of different techniques for in microgravity-a simple mathematic estimation of cardiopulmonary resuscitation quality for space environment. Am J Emerg Med. 2015;33(7):920-924. doi:10.1016/j. ajem.2015.04.018. 